\title{
Collaborative Care for Depression among Patients with Limited English Proficiency: a Systematic Review
}

\author{
Maria E. Garcia, MD MPH MAS ${ }^{7}$, Lisa Ochoa-Frongia, $\mathrm{MD}^{7}$, Nathalie Moise, $M D \mathrm{MS}^{2}$, \\ Adrian Aguilera, $\mathrm{PhD}^{3,4}$, and Alicia Fernandez, $M D^{7}$
}

'Department of General Internal Medicine, University of California, San Francisco, San Francisco, CA, USA; ${ }^{2}$ Center for Behavioral Cardiovascular Health, Columbia University Medical Center, New York, NY, USA; ${ }^{3}$ School of Social Welfare, University of California, Berkeley, Berkeley, CA, USA;

${ }^{4}$ Zuckerberg San Francisco General Hospital, Department of Psychiatry, University of California, San Francisco, San Francisco, CA, USA.

BACKGROUND: Patients with limited English proficiency (LEP) have high rates of depression, yet face challenges accessing effective care in outpatient settings. We undertook a systematic review to investigate the effectiveness of the collaborative care model for depression for LEP patients in primary care.

METHODS: We queried online PubMed, PsycINFO, CINAHL and EMBASE databases (January 1, 2000, to June 10, 2017) for quantitative studies comparing collaborative care to usual care to treat depression in adults with LEP in primary care. We evaluated the impact of collaborative care on depressive symptoms or on depression treatment. Two reviewers independently extracted key data from the studies and assessed risk of bias using the Cochrane bias and quality assessment tool (RCTs) and the Newcastle-Ottawa Quality Assessment Scale (non-RCTs).

RESULTS: Of 86 titles identified, 15 were included (representing 9 studies: 5 RCTs, 3 cohort studies, and 1 case-control study). Studies included 4859 participants; 2679 (55\%) reported LEP. The majority spoke Spanish (93\%). The wide variability in study design and outcome definitions precluded performing a meta-analysis. Followup ranged from 3 months to 2 years. Three of four highquality RCTs reported that 13-25\% more patients had improved depressive symptoms when treated with culturally tailored collaborative care compared to usual care; the last had high treatment in the control arm and found equal improvement. Two non-RCT studies suggest that Spanish-speaking patients may benefit as much as, if not more than, English-speaking patients treated with collaborative care. The remaining studies reported increased receipt of preferred depression treatment (therapy vs. antidepressants) in the intervention groups. Eight of nine studies used bilingual providers to deliver the intervention.

DISCUSSION: While limited by the number and variability of studies, the available research suggests that collaborative care for depression delivered by bilingual providers may be more effective than usual care among patients with LEP. Implementation studies of collaborative care, particularly among Asian and non-Spanish-speakers, are needed.

Received June 15, 2017

Revised October 13, 2017

Accepted November 17, 2017

Published online December 18, 2017
KEY WORDS: depression; collaborative care; systematic review; language barriers; limited English proficiency.

J Gen Intern Med 33(3):347-57

DOI: $10.1007 / \mathrm{s} 11606-017-4242-4$

(C) Society of General Internal Medicine 2017

\section{INTRODUCTION}

Patients with limited English proficiency (LEP) have among the highest rates of untreated depression. ${ }^{1}$ Depression has been associated with poor quality of life, increased health care costs and non-mental health service utilization, and poor management of other chronic conditions (including diabetes and heart disease), with subsequently increased risk of complications and earlier mortality. ${ }^{2-11}$ Numerous studies have documented lower access to mental health care among patients with LEP compared to English-speaking patients. ${ }^{112-15}$ Challenges and barriers to seeking depression care include difficulties navigating complex medical and mental health care systems, widespread stigma surrounding depression treatment, and reliance on interpreters during sensitive screening, diagnosis, and treatment. Patients with LEP may also contend with cultural factors that make it difficult to seek or engage in depression care. ${ }^{12,13,16}$ Patients with LEP are more apt to seek ${ }^{12,16}$ and receive ${ }^{17}$ mental health services in primary care than in specialty mental health settings. ${ }^{18}$ However, the mental health concerns of racial and ethnic minority patients-including patients with LEP - are more likely to go unnoticed by primary care providers, ${ }^{19}$ and patients with LEP often receive poorerquality mental health care when they do seek care. ${ }^{20}$ These challenges also impact clinicians, as care for patients with depression is often difficult when patients and clinicians do not share a common language and cultural heritage. Eliciting symptoms, establishing trust, and achieving treatment goals are usually more difficult across language barriers. ${ }^{21-24}$.

More than 80 randomized controlled trials (RCTs) and numerous systematic reviews have reported improved depressive symptoms, as well as positive effects on other comorbid conditions, when patients are treated using a collaborative care model. ${ }^{25-29}$ Key components of the collaborative care model include care coordination and care management with multidisciplinary team-based patient care. The care team includes a 
social worker or behavioral health assistant who engages the patient in regular care and monitors depressive symptoms using validated clinical ratings scales and population-based registries to facilitate active management, while communicating regularly with the primary care providers. A psychiatrist consults as needed for patients failing to achieve remission. ${ }^{30}$ While there is a broad research base supporting the collaborative care model among English-speaking patients, less is known about the effectiveness of this model in treating depressive symptoms among patients with LEP, who face additional barriers when seeking and engaging in mental health care.

We conducted a systematic review of the literature evaluating the effectiveness of collaborative care over usual care for the treatment of depressive symptoms among patients with LEP, while also gathering information about intervention adaptations to better serve the needs of this population.

\section{METHODS}

\section{Publication Search}

We searched PubMed, PsycInfo, Web of Science, and Embase for articles published between January 1, 2000 (before the collaborative model had been described), and June 10, 2017. Search syntaxes were developed in consultation with an experienced university research librarian, taking into account a broad range of terms and phrases used in defining randomized controlled trials (RCTs), cohort studies, collaborative care, depression, limited English proficiency, immigrants, and language barriers (details in Fig. 1). We also searched reference lists of retrieved articles and systematic reviews, and spoke to experts in the field. If the components of collaborative care were not clearly described in the publication, we emailed study investigators to obtain that information.

\section{Study Selection}

Studies that met all of the following criteria were included in this systematic review: 1) participants were adults ( $>18$ years old) with depressive symptoms identified either through routine clinical care or through the use of a validated depression screening tool; 2) study setting was outpatient only; 3) collaborative care, as defined by multidisciplinary team-based care, including a social worker or behavioral health assistant maintaining a registry of patients, and availability of a psychiatrist for consultation; 4) care delivered to patients with limited English proficiency (defined as (a) participants having language other than English listed as the preferred language, reporting need for interpretive services, or having a focus on first-generation immigrant populations from non-Englishspeaking countries, or (b) having greater than $75 \%$ non-

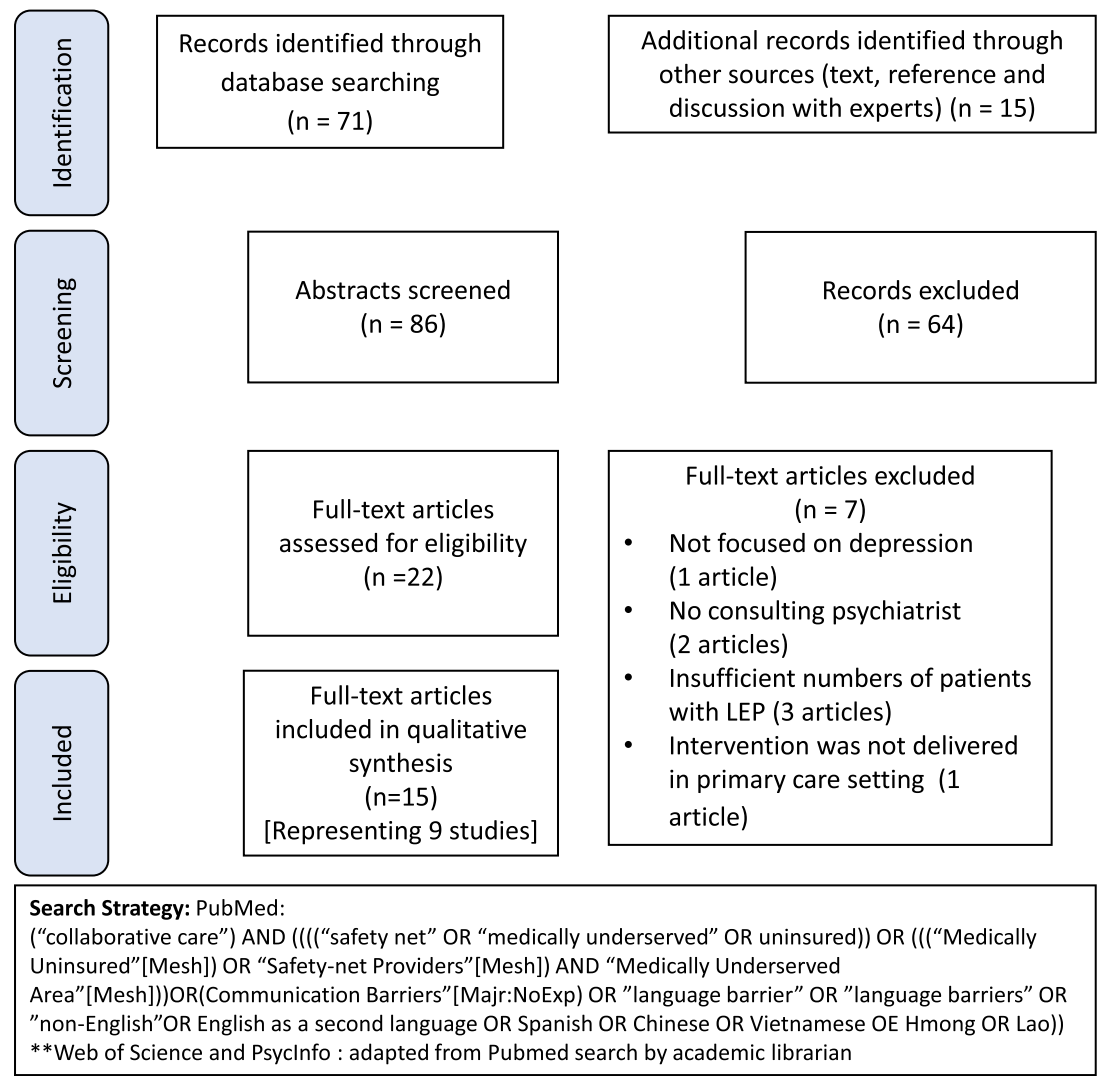

Figure 1 PRISMA flow diagram of study selection. 
English-speaking participants in the study even if the primary outcome was not reported by participant preferred language); and 5) outcomes included the impact of collaborative care on depressive symptoms or on depression treatment. Given the small number of RCTs among patients with LEP, we included other experimental designs in this review. We excluded studies on the basis of one or more of the following: 1) inappropriate population (e.g. children, adolescents, pregnant women, English-speaking only), 2) purely qualitative study design, or 3 ) collaborative care programs focused on the treatment of other medical conditions (e.g. chronic pain or substance use disorders) rather than depression or depressive symptoms.

Two investigators (MEG and LO-F) reviewed the titles and abstracts for all citations to identify studies that met inclusion criteria. If the reviewers could not determine from the abstract whether a particular study met inclusion criteria, the article advanced to a full text review. Articles that were selected for inclusion on the basis of the title and abstract also advanced to full-text review. We exported all studies obtained from the database searches to Covidence, ${ }^{31}$ a web-based program that allows collaborators to screen and review studies, assess quality, and resolve disagreements on inclusion and exclusion.

\section{Data Extraction}

We used a standardized data extraction form to collect the following: first author name, publication year, study design, study location, study period, patient inclusion and exclusion criteria, participant characteristics (age, gender, race/ethnicity, and preferred language), sample size (intervention/control), components of "collaborative care" and control conditions, cultural or linguistic tailoring of the model, length and frequency of follow-up, depression baseline and outcome measures, and main results (focusing on depression outcomes only).

\section{Quality Assessment}

Two authors (MEG and LO-F) independently assessed the methodological quality of RCTs using the Cochrane Collaboration's tool for assessing risk of bias. ${ }^{32}$ The few discrepancies in assessment were discussed until the investigators reached consensus. We used the Newcastle-Ottawa Scale to assess the methodological quality of cohort and case-control studies. ${ }^{33}$ The score for this scale is based on three categories: 1) selection of study groups and ascertainment of exposure, 2) comparability of study groups, and 3) standardized assessment of outcome of interest. The clinical variability in study design and outcome precluded performing a meta-analysis. In addition, while outcome inconsistency is usually assessed with a test for heterogeneity, problems of power can give misleading results (such as in our review, which is limited by the small number of studies and diverse outcomes). ${ }^{34}$ Finally, given that five of the nine studies originated from the same study group, a test of heterogeneity might be misleading. We could not assess for publication bias using a funnel plot, due to the low number of studies and differing outcomes.

\section{RESULTS}

\section{Study Characteristics and Quality Assessment}

Our search strategy yielded 71 articles, of which 13 were included. Text, references, and discussion with experts yielded an additional 15 articles, of which only two were included after full-text review.

Table 1 summarizes the basic characteristics of the included studies. Fifteen articles, ${ }^{35-49}$ representing nine studies with distinct patient populations (five randomized controlled trials, three cohort studies, and one case-control study), met the study criteria and are included in this review (see Fig. 1 for PRISMA flow diagram). All five RCTs compared collaborative care to either usual care or enhanced usual care (involving distribution of patient educational materials or resource lists for depression), and all were included for having $\geq 75 \%$ patients with LEP rather than for reporting outcomes by language preference. One article (Dwight-Johnson et al.) described the intervention as "collaborative care," but failed to specify the availability of a consulting psychiatrist; this component was confirmed via an email to the study investigators. ${ }^{36} \mathrm{We}$ observed substantial variation in sample size $(n=55-2821)$ as well as intervention duration ( 3 months to 2 years) and frequency of follow-up (every 2 weeks to every 6 months) across the studies (Table 1).

The reviewed studies were diverse in methodological approaches (Table 1). Two of the RCTs did not report on allocation concealment ${ }^{36,44}$; however, overall, the five RCTs were found to be at low risk for selection bias. None of the RCTs blinded participants or personnel to the intervention (Table 2). All five RCTs ascertained outcomes by blinded researchers/ care providers and had complete outcome data, with low risk for attrition or reporting bias. The non-RCTs did not have a usual care control group. ${ }^{46-48}$

Depression measures were generally well described. All studies employed the same widely used and validated screening instrument, the Patient Health Questionnaire-9 (PHQ-9), to determine baseline depression diagnosis. However, there was wide variability in the measures used to define study outcomes. To determine depressive symptom improvement, six of nine studies used the PHQ-9, two studies used the Hopkins Symptom Checklist Depression Scale (SCL-20; primarily used in research studies), and one study used the Hamilton Rating Scale for Depression (HAM-D-17), the Clinical Global Impression Severity Scale (CGI-S), and the Clinical Global Impression Improvement Scale (CGI; three scales primarily used in research rather than routine clinical care). One study reported that researchers used their own translation of the PHQ-9 to Chinese, which had been validated in a prior study. ${ }^{44,50}$ Other studies did not specify whether they used validated translations or translated their own instruments. ${ }^{35-}$ 41,43,45-49 All studies adequately described the interventions and the control conditions (if present in non-RCTs; "comparability" criteria in Table 3). 


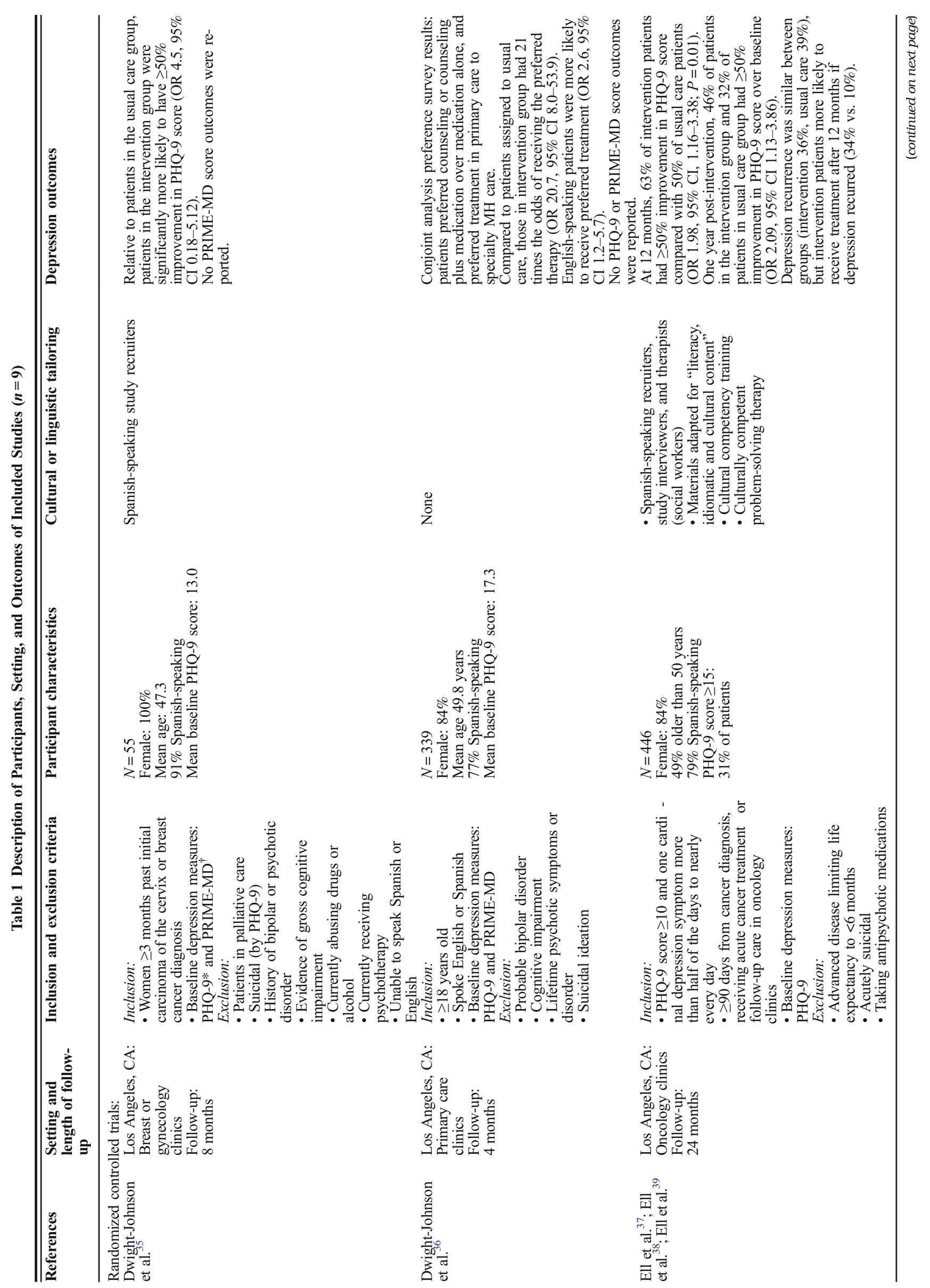




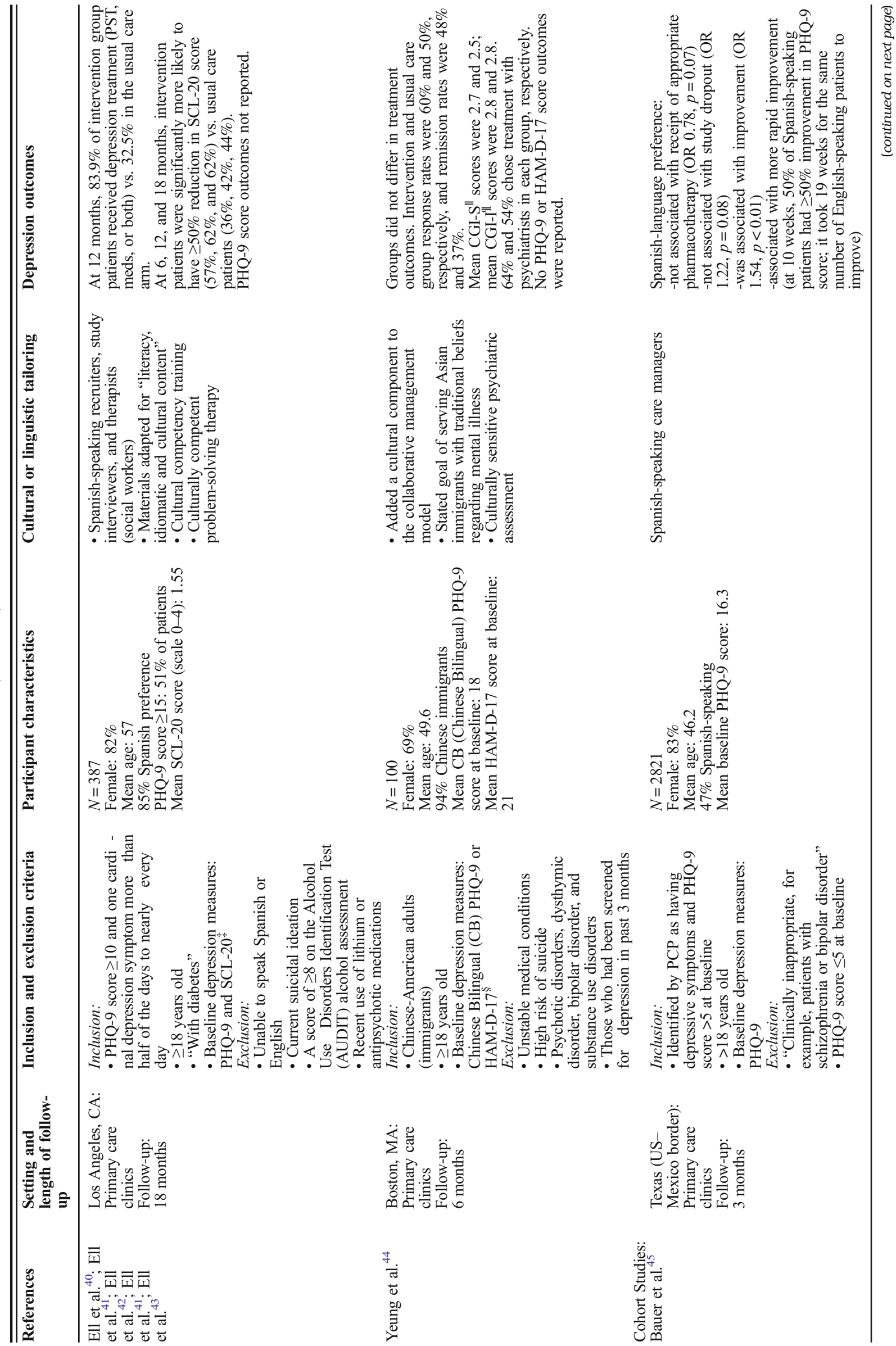




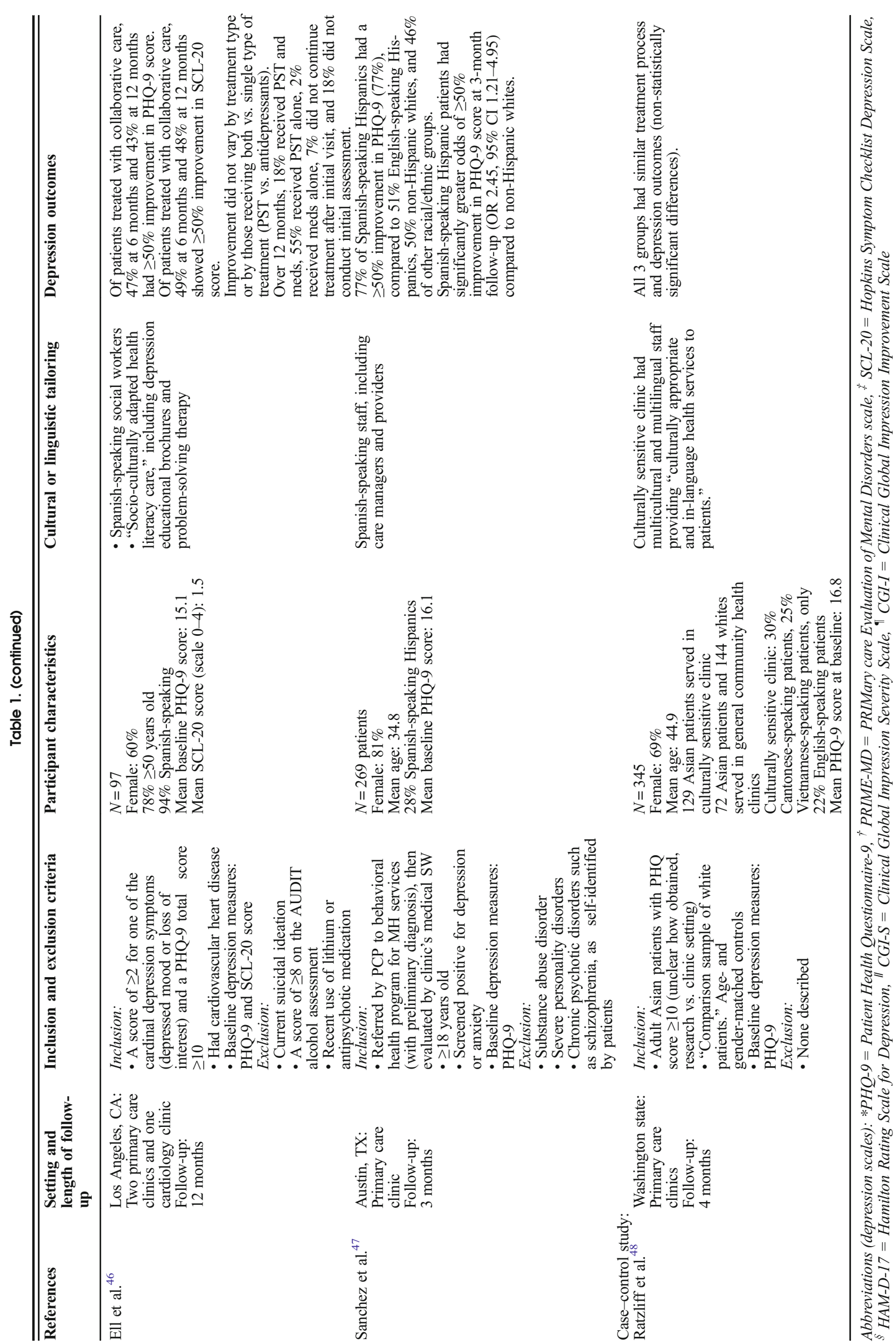


Table 2 Quality Assessment of Included RCT Studies Using the Cochrane Collaboration Tool for Assessing Risk of Bias

\begin{tabular}{|c|c|c|c|c|c|c|}
\hline \multirow[t]{2}{*}{ Reference } & \multicolumn{2}{|c|}{ Selection bias } & \multirow{2}{*}{$\begin{array}{l}\text { Performance } \\
\text { bias } \\
\text { Blinding of } \\
\text { participants } \\
\text { and personnel }\end{array}$} & \multirow{2}{*}{$\begin{array}{l}\text { Detection bias } \\
\text { Blinding of } \\
\text { outcome } \\
\text { assessment }\end{array}$} & \multirow{2}{*}{$\begin{array}{l}\text { Attrition Bias } \\
\text { Incomplete } \\
\text { outcome data }\end{array}$} & \multirow{2}{*}{$\begin{array}{l}\begin{array}{l}\text { Reporting } \\
\text { bias }\end{array} \\
\begin{array}{l}\text { Selective } \\
\text { reporting }\end{array}\end{array}$} \\
\hline & $\begin{array}{l}\text { Random } \\
\text { sequence } \\
\text { generation }\end{array}$ & $\begin{array}{l}\text { Allocation } \\
\text { concealment }\end{array}$ & & & & \\
\hline $\begin{array}{l}\text { Ell et al al. }{ }^{49} ; \text { Ell et al al }{ }^{42} ; \text { Ell } \\
\text { et al. }{ }^{39,41} ; \text { Ell et al. }{ }^{43}\end{array}$ & $\mathrm{~L}$ & $\mathrm{~L}$ & $\mathrm{H}$ & $\mathrm{L}$ & $\mathrm{L}$ & $\mathrm{L}$ \\
\hline $\begin{array}{l}\text { Ell et al }{ }^{37} \text {; Ell et al }{ }^{39,41} \\
\text { (ADAPt-C trial) }\end{array}$ & $\mathrm{L}$ & $\mathrm{L}$ & $\mathrm{H}$ & $\mathrm{L}$ & $\mathrm{L}$ & $\mathrm{L}$ \\
\hline Yeung et al. ${ }^{44}$ & $\mathrm{~L}$ & $\mathrm{U}$ & $\mathrm{H}$ & $\mathrm{L}$ & $\mathrm{L}$ & $\mathrm{L}$ \\
\hline Dwight-Johnson et al. ${ }^{35}$ & $\mathrm{~L}$ & $\mathrm{~L}$ & $\mathrm{H}$ & $\mathrm{L}$ & $\mathrm{L}$ & $\mathrm{L}$ \\
\hline Dwight-Johnson et al. ${ }^{36}$ & $\mathrm{~L}$ & $\mathrm{U}$ & $\mathrm{H}$ & $\mathrm{L}$ & $\mathrm{L}$ & $\mathrm{L}$ \\
\hline
\end{tabular}

$L=$ low risk of bias, $H=$ high risk of bias, $U=$ unknown risk of bias

Two studies reported post-intervention follow-up and included outcomes (primarily sustainability of intervention and depression remission) a year after the intervention had ended (total follow-up time 3 years). ${ }^{39,41}$ Not all studies reported how frequently care managers contacted patients in the intervention group during follow-up (or mean number of contacts).

Table 3 Quality Assessment of Included Non-RCT Studies

\begin{tabular}{|c|c|c|c|c|}
\hline $\begin{array}{l}\text { Reference } \\
\text { and setting }\end{array}$ & Patient selection & Methods/Statistical analysis & $\begin{array}{l}\text { Quality } \\
\text { assessment }\end{array}$ & Comments \\
\hline $\begin{array}{l}\text { Bauer et al. }{ }^{45} \\
\text { Texas }\end{array}$ & $\begin{array}{l}\text { Primarily uninsured, } \\
\text { urban and rural primary } \\
\text { care patients selected by } \\
\text { PCP. }\end{array}$ & $\begin{array}{l}\text { Logistic regression, accounted for clustering of } \\
\text { patients within clinics. ORs reported with no } \\
\text { CIs. } \\
\text { Cox proportional hazards models to estimate } \\
\text { time to improvement. }\end{array}$ & $\begin{array}{l}\text { Selection: } 3 / 4 \\
\text { Comparability: } \\
2 / 2 \\
\text { Outcome: } 2 / 3\end{array}$ & $\begin{array}{l}\text { Cohort study. } \\
\text { Data collection embedded in } \\
\text { clinical care. } \\
\text { Comparing English- to } \\
\text { Spanish-speaking individuals } \\
\text { with depression, no other con- } \\
\text { trol (no usual care or } \\
\text { non-intervention control). } \\
\text { May be subject to referral bias. }\end{array}$ \\
\hline Ell et al. ${ }^{46}$ & $\begin{array}{l}\text { Predominantly Hispanic, } \\
\text { foreign-born, Spanish- } \\
\text { speaking, and } \\
\text { unemployed. }\end{array}$ & $\begin{array}{l}T \text { tests for continuous variables, chi-square tests } \\
\text { for dichotomous variables. Proportions for } \\
\text { patients meeting definition of depression im- } \\
\text { provement compared by chi-square test. }\end{array}$ & $\begin{array}{l}\text { Selection: } 3 / 4 \\
\text { Comparability: } \\
0 / 2 \\
\text { Outcome: } 1 / 3\end{array}$ & $\begin{array}{l}\text { Cohort study with no control } \\
\text { group and high attrition rate } \\
(25 \% \text { at } 6 \text { months and } 40 \% \text { at } \\
12 \text { months). }\end{array}$ \\
\hline$\underset{48}{\text { Ratzliff et al. }}$ & $\begin{array}{l}\text { Minimal patient } \\
\text { characteristics described. }\end{array}$ & $\begin{array}{l}\text { Chi-square tests and } t \text { test for baseline } \\
\text { characteristics. }\end{array}$ & $\begin{array}{l}\text { Selection: } 4 / 4 \\
\text { Comparability: }\end{array}$ & $\begin{array}{l}\text { Case-control study of existing } \\
\text { collaborative care program (no }\end{array}$ \\
\hline $\begin{array}{l}\text { Washington } \\
\text { state }\end{array}$ & $\begin{array}{l}\text { Appear to rely on EMR } \\
\text { for identification of } \\
\text { eligible participants. }\end{array}$ & $\begin{array}{l}\text { Mixed-effects logistic modeling for binary } \\
\text { outcomes and mixed-effects Poisson modeling } \\
\text { for count of follow-up contacts, taking account } \\
\text { nesting in participating clinics. } \\
\text { Last-observation-carried-forward approach. }\end{array}$ & $\begin{array}{l}2 / 2 \\
\text { Outcome: } 2 / 3\end{array}$ & $\begin{array}{l}\text { usual care or non-intervention } \\
\text { control). } \\
\text { Uses intention to treat analysis. } \\
\text { Very poor characterization of } \\
\text { languages spoken by } \\
\text { participants. } \\
\text { Data collection embedded in } \\
\text { clinical care. } \\
\text { May be subject to selection bias. }\end{array}$ \\
\hline $\begin{array}{l}\text { Sanchez } \\
\text { et al. } 47\end{array}$ & $\begin{array}{l}\text { Predominantly Hispanic, } \\
\text { low-income population in } \\
\text { a primary care setting; no } \\
\text { info on insurance status. } \\
\text { Patients selected by PCP. }\end{array}$ & $\begin{array}{l}\text { Chi-square and analysis of variance tests for } \\
\text { baseline characteristics and change in } \\
\text { depression severity over time. } \\
\text { Logistic regression modeling to compare the } \\
\text { various race/ethnicity and language groups. } \\
\text { Loss to follow-up not mentioned (nor intention } \\
\text { to treat analysis). }\end{array}$ & $\begin{array}{l}\text { Selection: } 3 / 4 \\
\text { Comparability: } \\
2 / 2 \\
\text { Outcome: } 2 / 3\end{array}$ & $\begin{array}{l}\text { Retrospective cohort study, } \\
\text { evaluation of existing program } \\
\text { (no usual care or non- } \\
\text { intervention group). } \\
\text { Data collection embedded in } \\
\text { clinical care. } \\
\text { May be subject to referral bias } \\
\text { LTFU not reported. }\end{array}$ \\
\hline
\end{tabular}

Newcastle-Ottawa Quality Assessment Scale Categories

A. Selection (maximum 4)

1 Representativeness of the exposed cohort

2 Selection of the non-exposed cohort

3 Ascertainment of exposure

4 Demonstration that outcome of interest was not present at start of study

B. Comparability (maximum 2)

Control $=$ English-speaking or not receiving the intervention

1 Study controls (receiving usual care or other intervention)

2 Study controls for additional factors

C. Outcome (maximum 3)

1 Assessment of outcome (independent blind assessment, record linkage)

2 Was follow-up long enough for outcomes to occur?

3 Adequacy of follow-up of cohorts (complete or lost to follow-up unlikely to introduce bias?)

Total (maximum 9) 


\section{Characteristics of Study Participants}

The mean age ranged from 34.8 to 57 years across studies, and 1166 of 4859 participants (24\%) were male. Among the nine studies, 2679 participants (55\%) had LEP. Most studies focused on Latino immigrants living in the United States (primarily Mexican-Americans living in Los Angeles), with Spanish as the preferred language e $^{35-41,43,45-47,49}$; only two studies included Chinese and Vietnamese immigrants. ${ }^{44,48}$ The majority of LEP participants (2484, or 93\%) spoke Spanish. One hundred and ninety-five patients with LEP spoke Mandarin, Cantonese, or Vietnamese (7\%). Two studies ${ }^{44,48}$ had poor characterization of participant languages, noting that many spoke "Asian languages," and citing only clinic language demographics (rather than individual study participant preferred language). In two studies reporting that patients preferred a non-English language, the degree of English language proficiency was not described. ${ }^{45,47}$

Three-quarters of participants were recruited from general primary care $(3748 / 4859,77 \%$; either through screening in waiting rooms or through referral from PCP) and had a variety of medical conditions. Other participants $(23 \%)$ were recruited into the studies for specific comorbidities (diabetes [8\%], breast or gynecological cancer [11\%], and cardiovascular disease [2\%]).

\section{Cultural or Linguistic Tailoring of the Collaborative Care Model}

While intervention details were not always fully described, eight of nine studies employed bilingual care managers (mainly social workers) for the delivery of care in the collaborative care model. ${ }^{36-49}$ The ninth study did not explicitly mention how the intervention was delivered to patients with LEP. ${ }^{35}$ No studies reported on the use of interpreters. Three RCTs and two non-RCTs reported on culturally sensitive or culturally adapted interventions ("cultural or linguistic tailoring"; see Table 1). These five studies explicitly tailored their interventions to different cultural groups. ${ }^{37-44,48,49}$ The two RCTs and one non-RCT serving Spanish-speaking patients, all conducted by the same research group, culturally tailored the collaborative care model by adapting the intervention materials for literacy and for idiomatic and cultural content. They further included cultural competency training for staff and employed bilingual staff to conduct the intervention. ${ }^{37-42,46,49}$ The remaining studies ${ }^{44,48}$ mentioned adding a cultural component to the collaborative care model with the goal of serving Asian immigrants with traditional beliefs about mental illness. One study further adapted the psychiatric assessment for cultural sensitivity. ${ }^{44}$

\section{Randomized Controlled Trials (RCTs)}

Change in Depressive Symptoms. Four of five RCTs reported on change in depressive symptoms; none reported outcomes by preferred language group. Three RCTs reported that the proportion of patients who experienced $\mathrm{a} \geq 50 \%$ reduction in depressive symptoms score was $13 \%$ to $25 \%$ greater in the intervention arm than in usual care (Table 1). ${ }^{35,37-43,49}$ The last RCT, Yeung et al., reported no statistically significant difference between treatment groups at 6 months ${ }^{44}$; however, the investigators noted availability and high uptake of psychiatric services in both study arms (64\% of intervention group vs. 54\% of usual care control group chose treatment with psychiatrists). Three of these four RCTs included cultural tailoring of their interventions. ${ }^{37-44,49}$

\section{Differences in Receipt of Depression Treatment and} Treatment Preferences. Two RCTs reported on receipt of depression treatment and treatment preferences. In one RCT, $84 \%$ of patients treated in the collaborative care intervention received depression treatment (psychotherapy, antidepressants, or both), compared to only $33 \%$ of patients in the enhanced usual care arm, over 12 months of follow-up..$^{39,40,43,49}$ Another RCT focused on depression treatment preferences. ${ }^{36}$ Using conjoint analysis preference surveys, this study found that patients (77\% Spanish-speaking) preferred counseling or counseling plus medication over antidepressants alone, and that patients preferred treatment in primary care rather than in specialty mental health care. Patients in the collaborative care intervention group were much more likely to receive their preferred treatment at 16 weeks than were patients in usual care (OR 20.7, 95\% CI 8.0-53.9). However, this study also found that English speakers in both groups were more likely to receive their preferred treatment modality than their Spanishspeaking counterparts (OR 2.6, 95\% CI 1.2-5.7). ${ }^{36}$

Non-Randomized Controlled Studies (3 Cohort Studies and 1 Case-Control Study). One non-RCT study ${ }^{46}$ found that $49 \%$ and $48 \%$ of patients reported improved depressive symptoms (measured with the SCL-20 and PHQ-9 scales) at 6 and 12 months, respectively, among study participants treated with collaborative care. The two studies ${ }^{45,47}$ that reported outcomes by preferred language found significant differences between English- and Spanish-speaking patients. Bauer et al. found that Spanish language preference was associated with more rapid and greater overall improvement (OR 1.54, $p<0.01$, CIs not reported), when compared to English preference, despite not being associated with receipt of appropriate pharmacotherapy. ${ }^{45}$ Similarly, Sanchez et al. found that Spanish-speaking Hispanic patients had significantly greater odds of achieving clinically meaningful improvement in depressive symptoms at 3-month follow-up than did non-Hispanic whites (OR 2.45, $95 \%$ CI $1.21-4.95) .{ }^{47}$

In contrast, Ratzliff et al. found similar treatment process and depression outcomes at 16 weeks among three groups treated with collaborative care: Asians treated at a culturally sensitive clinic, Asians treated at a general clinic, and whites treated at a general clinic (though language characteristics of participants were not clearly defined, and it is unclear whether there was a difference in primary language between Asians treated at the culturally sensitive clinic and those treated in the 
general clinic) ${ }^{48}$ Furthermore, the study did not have a usual care control group to enable evaluation of the intervention. ${ }^{48}$

\section{DISCUSSION}

Despite the existence of effective treatment, depression care for patients with LEP is challenging for both patients and clinicians, and better models of care are needed. In a systematic review of the current literature on outpatient, primary carebased collaborative care treatment of depression, we found that collaborative care delivered by bilingual providers was more effective than usual care in treating depressive symptoms among patients with LEP.

The systematic review revealed important limitations in the current evidence base. The review was limited by the low number of studies (particularly for non-Spanish-language groups), heterogeneity of study outcomes and definitions, and a lack of data on use of language access services. However, the randomized controlled studies were consistent in treatment effect size, as three of four high-quality RCTs found that $13 \%-25 \%$ more patients reported improved depressive symptoms when treated with collaborative care compared to usual care; the fourth had unusually high rates of treatment in the comparison arm and found no difference between groups. ${ }^{35,37-44,49}$ This is consistent with prior systematic reviews of collaborative care treatment. ${ }^{26-29,51}$ Review of two cohort studies that reported outcomes by preferred language found similar-sized improvements as $10 \%$ and $27 \%$ more Spanish-speaking patients had improved depressive symptoms during 3 months of follow-up when treated with collaborative care, indicating that patients with LEP may benefit as much as, if not more than, English-speaking patients treated with collaborative care. ${ }^{45,47}$ In short, the collaborative care model - with its emphasis on regular screening, standardized metrics, validated instruments, proactive management, and individualized care, and when adapted for care of LEP patients with depression via the use of bilingual providers - appears to improve care for this patient population.

Yet while the collaborative care model has performed well in research studies, many questions remain for wider implementation and dissemination in systems caring for patients with LEP. To help guide the dissemination of an effective model of collaborative care for patients with LEP, researchers will need to be more specific in detailing the language skills of participants (including their English language proficiency) and any cultural tailoring and adaptations made to the model to serve specific populations, as we found that race and ethnicity are often conflated with language in these studies, and that preferred language and degree of English language proficiency is not always made explicit. Language barriers may increase the possibility of diagnostic assessment bias, diagnostic errors, and decreased engagement and retention in depression care. ${ }^{52,53}$ It is important to note that most studies employed bilingual staff; language concordance may be particularly important when dealing with mental health concerns, as it is associated with increased patient trust in providers, improved adherence to medications, and increased shared decision-making. ${ }^{21,54-57}$ Furthermore, the collaborative care model may have been addressing cultural barriers to care beyond linguistic barriers. While a few of the studies culturally adapted and modified their collaborative care model and their psychiatric assessments, these adaptations were not addressed in detail and may be difficult to replicate in other settings. Best practices for culturally adapting collaborative care for patients with LEP have yet to be defined. Further research is also needed to more rigorously ascertain the effectiveness of cultural versus linguistic tailoring on the effectiveness of collaborative care in LEP groups.

Additionally, given the evidence that depression in racial and ethnic minorities and patients with LEP often goes unrecognized, ${ }^{19,44}$ efforts will be needed to make sure these groups are systematically screened for depressive symptoms and referred for care in culturally sensitive ways. One large implementation study in the state of Minnesota found a marked difference in enrollment into collaborative care by LEP status. ${ }^{58}$ Of those eligible for a non-research-oriented collaborative care model, only $18.2 \%$ of eligible LEP patients were enrolled over a 3 -year period, compared to $47.2 \%$ of eligible English-speaking patients (adjusted OR 0.43, 95\% CI 0.230.81 ). Similarly, Asian patients were underrepresented in studies and likely in collaborative care programs. Yeung et al. reported that the majority of Chinese immigrants with depression were under-recognized and undertreated in primary care, as evidenced by the fact that only $7 \%$ of patients who screened positive for depression were engaged in treatment in primary care clinics in Massachusetts. ${ }^{44}$

Referral processes for collaborative care may also need to be improved for patients with LEP. The reasons for differences in enrollment by LEP status in collaborative care programs remain poorly elucidated ${ }^{58}$ and likely include patient-, provider-, and systems-based factors. However, these results suggest that without targeted efforts to screen, enroll, and engage patients with LEP, collaborative care models may only widen mental health disparities for such patients. Studies that examine implementation and sustainability of the collaborative care model are needed.

This review has a number of limitations. We may have missed studies where language and participant origin were not adequately described. Additionally, as has been noted in prior systematic reviews of RCTs of collaborative care, participant and provider blinding would not have been feasible, due to the nature of the interventions. ${ }^{59}$ Other limitations include the variability in study duration and outcome assessment, making direct outcome comparison difficult. Finally, of the nine studies included in this review, five were conducted in Los Angeles, CA (and by the same group of research investigators). This may limit the generalizability of our results. ${ }^{35-}$ $41,43,46,49$ 


\section{CONCLUSIONS}

This systematic review suggests that collaborative care delivered by bilingual providers is an effective model for the treatment of depression among patients with LEP (with stronger evidence among Spanish-speaking patients). The review is limited by the small number of participants with LEP and the variability in study design and outcomes. More research is needed on individuals speaking Asian and other non-Spanish languages and on best practices for actively screening, recruiting, and engaging patients with LEP in depression care. Finally, implementation studies are needed in real-world clinical care settings to identify key components of collaborative care and the effectiveness of this model across diverse settings.

Acknowledgements: We wish to thank Evans Whitaker for his iterative help with database and literature searches as the research question was defined over time. We also wish to thank SF BUILD (Building Infrastructure Leading to Diversity) for their support in the preparation of the final manuscript at a writing retreat.

Corresponding Author: Maria E. Garcia, MD MPH MAS; Department of General Internal Medicine University of California, San Francisco, San Francisco, CA, USA (e-mail: maria.garcia@ucsf.edu).

Funding Source Dr. Garcia received funding from HRSA Grant T32HP19025 for Faculty Development in Primary Care. This work was previously presented as an oral presentation at the Society for General Internal Medicine (SGIM) Annual conference in Washington, DC, on April 22, 2017.

\section{Compliance with Ethical Standards:}

Conflict of Interest: The authors declare that they do not have a conflict of interest.

\section{REFERENCES}

1. Njeru JW, DeJesus RS, Sauver JS, et al. Utilization of a mental health collaborative care model among patients who require interpreter services. Int J Mental Health Syst. 2016; 10.

2. Palinkas LA, Lee PP, Barrett-Connor E. A prospective study of type 2 diabetes and depressive symptoms in the elderly: the Rancho Bernardo Study. Diabet Med. 2004;21(11):1185-1191.

3. Black SA, Markides KS, Ray LA. Depression predicts increased incidence of adverse health outcomes in older Mexican Americans with type 2 diabetes. Diabetes Care. 2003;26(10):2822-2828.

4. Fortmann AL, Gallo LC, Walker C, Philis-Tsimikas A. Support for disease management, depression, self-care, and clinical indicators among Hispanics with type 2 diabetes in San Diego County, United States of America. Rev Panam Salud Publica. 2010;28(3):230-234.

5. Wu JH, Haan MN, Liang J, Ghosh D, Gonzalez HM, Herman WH. Impact of diabetes on cognitive function among older Latinos: a population-based cohort study. J Clin Epidemiol. 2003;56(7):686-693.

6. Johnson LA, Gamboa A, Vintimilla R, et al. Comorbid depression and diabetes as a risk for mild cognitive impairment and Alzheimer's Disease in elderly Mexican Americans. J Alzheimers Dis. 2015;47(1):129-136.

7. Sumlin LL, Garcia TJ, Brown SA, et al. Depression and adherence to lifestyle changes in type 2 diabetes: a systematic review. Diabetes Educ. 2014;40(6):731-744.

8. de Groot M, Anderson R, Freedland KE, Clouse RE, Lustman PJ. Association of depression and diabetes complications: a meta-analysis. Psychosom Med. 2001;63(4):619-630.

9. Egede LE, Zheng $\mathbf{D}$, Simpson $\mathbf{K}$. Comorbid depression is associated with increased health care use and expenditures in individuals with diabetes. Diabetes Care. 2002;25(3):464-470.
10. Davydow DS, Katon JG, Rollman BL, Unutzer J. Improving mental and physical health outcomes in general healthcare settings: a Gedenkschrift in honor of Wayne Katon, MD (1950-2015). Gen Hosp Psychiatry. 2015;37(5):375-386.

11. Hofmann M, Kohler B, Leichsenring F, Kruse J. Depression as a risk factor for mortality in individuals with diabetes: a meta-analysis of prospective studies. PLoS One. 2013;8(11):e79809.

12. Sentell T, Shumway M, Snowden $\mathbf{L}$. Access to mental health treatment by English language proficiency and race/ethnicity. J Gen Intern Med. 2007;22 Suppl 2:289-293.

13. Kim G, Aguado Loi CX, Chiriboga DA, Jang Y, Parmelee P, Allen RS. Limited English proficiency as a barrier to mental health service use: a study of Latino and Asian immigrants with psychiatric disorders. J Psychiatr Res. 2011;45(1):104-110.

14. Bauer AM, Chen CN, Alegria M. English language proficiency and mental health service use among Latino and Asian Americans with mental disorders. Med Care. 2010;48(12):1097-1104.

15. Alegria M, Chatterji P, Wells K, et al. Disparity in depression treatment among racial and ethnic minority populations in the United States. Psychiatr Serv. 2008;59(11):1264-1272.

16. Cabassa LJ, Zayas LH, Hansen MC. Latino adults' access to mental health care: a review of epidemiological studies. Adm Policy Ment Health. 2006;33(3):316-330.

17. Lee S, Laiewski L, Choi S. Racial-ethnic variation in U.S. mental health service use among Latino and Asian non-U.S. citizens. Psychiatr Serv. 2014;65(1):68-74.

18. Njeru JW, St. Sauver JL, Jacobson DJ, et al. Emergency department and inpatient health care utilization among patients who require interpreter services Utilization, expenditure, economics and financing systems. BMC Health Serv Res. 2015;15(1).

19. Borowsky SJ, Rubenstein LV, Meredith LS, Camp P, Jackson-Triche $\mathbf{M}$, Wells KB. Who is at risk of nondetection of mental health problems in primary care? J Gen Intern Med. 2000;15(6):381-388.

20. U.S. Department of Health and Human Services. Mental Health: Culture, Race, and Ethnicity: A Supplement to Mental Health: A Report of the Surgeon General. Rockville MD2001.

21. Karliner LS, Jacobs EA, Chen AH, Mutha S. Do professional interpreters improve clinical care for patients with limited English proficiency? A systematic review of the literature. Health Serv Res. 2007;42(2):727754 .

22. Schenker Y, Karter AJ, Schillinger D, et al. The impact of limited English proficiency and physician language concordance on reports of clinical interactions among patients with diabetes: the DISTANCE study. Patient Educ Couns. 2010;81(2):222-228.

23. Fernandez A, Quan J, Moffet H, Parker MM, Schillinger D, Karter AJ. Adherence to newly prescribed diabetes medications among insured Latino and White patients with diabetes. JAMA Intern Med. 2017.

24. Parker MM, Fernandez A, Moffet HH, Grant RW, Torreblanca A, Karter AJ. Association of patient-physician language concordance and glycemic control for Limited-English Proficiency Latinos with type 2 diabetes. JAMA Intern Med. 2017;177(3):380-387.

25. Wetherell JL, Unutzer J. Adherence to treatment for geriatric depression and anxiety. CNS Spectr. 2003;8(12 Suppl 3):48-59.

26. van der Feltz-Cornelis $\mathbf{C M}$, Nuyen $\mathbf{J}$, Stoop $\mathbf{C}$, et al. Effect of interventions for major depressive disorder and significant depressive symptoms in patients with diabetes mellitus: a systematic review and meta-analysis. Gen Hosp Psychiatry. 2010;32(4):380-395.

27. Huang Y, Wei X, Wu T, Chen R, Guo A. Collaborative care for patients with depression and diabetes mellitus: a systematic review and metaanalysis. BMC Psychiatry. 2013;13:260.

28. Katon WJ, Lin EH, Von Korff $\mathbf{M}$, et al. Collaborative care for patients with depression and chronic illnesses. N Engl J Med. 2010;363(27):26112620.

29. Atlantis E, Fahey P, Foster J. Collaborative care for comorbid depression and diabetes: a systematic review and meta-analysis. BMJ Open. 2014;4(4):e004706.

30. Unützer J HH, Schoenbaum M, Druss B. The Collaborative Care Model: An Approach for Integrating Physical and Mental Health Care in Medicaid Health Homes: Brief. 2013.

31. Covidence systematic review software. Veritas Health Innovation, Melbourne, Australia. Available at www.covidence.org. Accessed October 25, 2017.

32. Higgins JP, Altman DG, Gotzsche PC, et al. The Cochrane Collaboration's tool for assessing risk of bias in randomised trials. BMJ. 2011;343:d5928. 
33. Wells GA SB, O'Connell D, Peterson J, Welch V, Losos M, Tugwell P. The Newcastle-Ottawa scale (NOS) for assessing the quality of nonrandomised studies in meta-analyses. http://www.ohri.ca/programs/clinical_epidemiology/oxford.asp. 2009. Accessed October 25, 2017.

34. Higgins JP, Thompson SG, Deeks JJ, Altman DG. Measuring inconsistency in meta-analyses. BMJ. 2003;327(7414):557-560.

35. Dwight-Johnson $\mathbf{M}$, Ell $\mathbf{K}$, Lee PJ. Can collaborative care address the needs of low-income Latinas with comorbid depression and cancer? Results from a randomized pilot study. Psychosomatics. 2005;46(3):224232.

36. Dwight-Johnson M, Lagomasino IT, Hay J, et al. Effectiveness of Collaborative Care in Addressing Depression Treatment Preferences Among Low-Income Latinos. Psychiatr Serv. 2010;61(11):1112-1118.

37. Ell K, Quon B, Quinn DI, et al. Improving treatment of depression among low-income patients with cancer: the design of the ADAPt-C study. Gen Hosp Psychiatry. 2007;29(3):223-231.

38. Ell K, Xie B, Guon B, Quinn DI, Dwight-Johnson M, Lee PJ. Randomized controlled trial of collaborative care management of depression among low-income patients with cancer. J Clin Oncol. 2008;26(27):4488-4496.

39. Ell K, Katon W, Xie B, et al. One-year postcollaborative depression care trial outcomes among predominantly Hispanic diabetes safety net patients. Gen Hosp Psychiatry. 2011;33(5):436-442.

40. Ell K, Katon W, Cabassa LJ, et al. Depression and diabetes among lowincome Hispanics: Design elements of a socio-culturally adapted collaborative care model randomized controlled trial. Int $\mathrm{J}$ Psychiatr Med. 2009;39(2):113-132.

41. Ell K, Xie B, Kapetanovic S, et al. One-year follow-up of collaborative depression care for low-income, predominantly Hispanic patients with cancer. Psychiatr Serv. 2011;62(2):162-170.

42. Ell K, Aranda MP, Xie B, Lee PJ, Chou CP. Collaborative Depression Treatment in Older and Younger Adults With Physical Illness: pooled comparative analysis of three randomized clinical trials. Am J Geriatr Psychiatry. 2010;18(6):520-530.

43. Ell K, Katon W, Lee PJ, et al. Depressive symptom deterioration among predominantly Hispanic diabetes patients in safety net care. Psychosomatics. 2012;53(4):347-355.

44. Yeung A, Shyu I, Fisher L, Wu S, Yang H, Fava M. Culturally sensitive collaborative treatment for depressed Chinese Americans in primary care. Am J Public Health. 2010;100(12):2397-2402.

45. Bauer AM, Azzone V, Alexander L, Goldman HH, Unutzer J, Frank RG. Are patient characteristics associated with quality of depression care and outcomes in collaborative care programs for depression? Gen Hosp Psychiatry. 2012;34(1): 1-8.
46. Ell K, Oh H, Lee PJ, Guterman J. Collaborative health literate depression care among predominantly Hispanic patients with coronary heart disease in safety net care. Psychosomatics. 2014;55(6):555-565.

47. Sanchez K, Watt TT. Collaborative care for the treatment of depression in primary care with a low-income, Spanish-speaking population: outcomes from a community-based program evaluation. Prim Care Companion CNS Disord. 2012;14(6).

48. Ratzliff AD, Ni K, Chan YF, Park M, Unutzer J. A collaborative care approach to depression treatment for Asian Americans. Psychiatr Serv. 2013;64(5):487-490.

49. Ell K, Katon W, Xie B, et al. Collaborative Care Management of Major Depression Among Low-Income, Predominantly Hispanic Subjects With Diabetes A randomized controlled trial. Diabetes Care. 2010;33(4):706-713.

50. Yeung A, Fung F, Yu SC, et al. Validation of the Patient Health Questionnaire-9 for depression screening among Chinese Americans. Compr Psychiatry. 2008;49(2):211-217.

51. Unutzer J, Katon W, Callahan CM, et al. Collaborative care management of late-life depression in the primary care setting: a randomized controlled trial. JAMA. 2002;288(22):2836-2845.

52. Kirmayer LJ, Groleau D, Guzder J, Blake C, Jarvis E. Cultural consultation: a model of mental health service for multicultural societies. Can J Psychiatry. 2003;48(3):145-153.

53. Alegria M, Mulvaney-Day $\mathbf{N}$, Woo $\mathbf{M}$, Torres $\mathbf{M}$, Gao S, Oddo V. Correlates of past-year mental health service use among Latinos: results from the National Latino and Asian American Study. Am J Public Health. 2007;97(1):76-83.

54. Weech-Maldonado R, Morales LS, Elliott M, Spritzer K, Marshall G, Hays RD. Race/ethnicity, language, and patients' assessments of care in Medicaid managed care. Health Serv Res. 2003;38(3):789-808.

55. Fernandez A, Schillinger D, Warton EM, et al. Language barriers, physician-patient language concordance, and glycemic control among insured Latinos with diabetes: the Diabetes Study of Northern California (DISTANCE). J Gen Intern Med. 2011;26(2):170-176.

56. Talamantes E, Moreno G, Guerrero LR, Mangione CM, Morales LS. Hablamos juntos (together we speak): a brief patient-reported measure of the quality of interpretation. Patient Relat Outcome Meas. 2014;5:87-92.

57. Karliner LS, Auerbach A, Napoles A, Schillinger D, Nickleach D, Perez-Stable EJ. Language barriers and understanding of hospital discharge instructions. Med Care. 2012;50(4):283-289.

58. Njeru JW, DeJesus RS, St. Sauver J, et al. Utilization of a mental health collaborative care model among patients who require interpreter services. Int J Ment Heal Syst. 2016;10.

59. Antoniades J, Mazza D, Brijnath B. Efficacy of depression treatments for immigrant patients: results from a systematic review. BMC Psychiatry. 2014;14: 176. 